\title{
Un balance de la ejecución de los acuerdos de paz en El Salvador
}

\author{
Carlos M. Vilas \\ UNAM. Centro de Investigaciones Interdisciplinarias en Ciencias y Humanidades (CIICH). \\ Torre 2 de Humanidades, $4^{\circ}$ piso, Ciudad Universitaria, UNAM. 04510 México DF. \\ Fax: (525) 617.4174 \\ VILAS@SERVIDOR.UNAMMX
}

\section{Resumen}

El arrículo evalua el proceso de implementación de los acuerdos de paz de El Salvador. En la primera parte, se analiza el estado actual de ejecución de cada uno de los aspectos fundamentales de los acuerdos: desmilitarización, derechos humanos, democratización y transferencia de tierras. Posteriormente, cl autor examina los rasgos básicos del contexto socioeconómico y los impactos del proceso de paz sobre los actores políticos. El artículo acaba ofreciendo algunas reflexiones de futuro sobre la realidad política y las políticas públicas en El Salvador.

Palabras clave: pacificación, políticas públicas, actores políticos, El Salvador.

\section{Abstract. An assessment of the implementation of the peace agreements in El Salvador}

The article addresses the implementation of the Salvadoran Peace agreements. In the first part of the paper each main aspect of theses agreements and its actual implementation is described: democratization, demilitarization, human rights and socio-economic policies. In the second section, the implications of these changes for the main Salvadoran political actors are discussed. The article ends with a short overview about some possible future evolurions of both politics and policies in the country.

Key words: peace process, public policies, political actors, El Salvador.

\section{Sumario}

I. Cumplimiento de los acuerdos de paz

II. El contexto socioeconómico
IIl. Realineaciones en

el terreno de la política

IV. Mirando hacia adelante 
En abril de 1995 ONUSAL, la misión de la ONU encargada de la verificación de los acuerdos de paz en El Salvador, dio por técnicamente funalizado sut cometido y se retiró del país, dejando solamente una muy reducida dotación de personal. La salida de ONUSAL marca el fin del período fijado por el Gobierno de EI Salvador y el FMLN (Frente Farabundo Martí de Liberación Nacional) en los acuerdos para el cumplimiento de los compromisos ahí establecidos, y que había sido prorrogado por decisión de ambas partes. La conclusión de ONUSAL tuvo lugar en un escenario de avance sustancial pero desigual de los acuerdos, varios de los cuales aún distan de haberse ejecutado.

El objeto de este trabajo es llevar a cabo una valoración del cumplimiento de los acuerdos de paz, discutiendo el escenario institucional y social que se está configurando a partir de ellos. El panorama que se discierne conjuga avances significativos en materia de libertades y garantías cívicas y políticas y de derechos humanos, con la persistencia de fuertes desigualdades e injusticias en materia social y económica. El pluralismo político se articula a una política económica de exclusión social, y la reactivación económica coexiste con elevados índices de empobrecimiento, en un contexto de desmovilización social.

\section{Cumplimiento de los acuerdos de paz}

Muy esquemáticamente, hacia abril de 1995 la situación de los acuerdos era la siguiente:

\section{Desmilitarización}

Aproximadamente la mitad de los efectivos de la Fuerza Armada de El Salvador (FAES) fue desmovilizada, y todos los mandos superiores que condujeron la guerra pasaron a retiro; los cuerpos de seguridad fueron disueltos y la nueva Policía Nacional Civil (PNC) completó su despliegue en todo el territorio nacional, sustituyendo a la antigua y corrupta Polića Nacional que dependfa de la FAES. Ésta, a sut vez, quedó privada de casi todas las atribuciones constitucionales que las erigían en tutor de la vida institucional; la pérdida de poder politico deterioró la imagen tradicional de la FAES como canal seguro de enriquecimiento para sus jefes y oficiales. La desmilitarización incluyó a las empresas y agencias gubernamentales cuya dirección era asignada a oficiales militares (telecomunicaciones, aduanas, electricidad, puertos y otras). La desmilitarización de estas áreas de la Administración gubernamental fue emprendida durante el presente gobierno del presidente Armando Calderón Sol, ya que su antecesor Alfredo Cristiani se había resistido a eilo, obedeciendo a las presiones de la FAES. Está funcionando el Colegio de Altos Estudios estratégicos para ofciales superiores de la FAES, como parte del desarrollo de una nueva doctrina de defensa nacional basada en la subordinación militar a las autoridades civiles.

La reducción de la FAES en tamaño y atribuciones no se refleja en dinero; el presupuesto militar para 1995 es de casi unos 100 millones (un $8 \%$ del gasto gubernamental total), prácticamente igual al de 1993 y sólo un $6 \%$ menor al de 1992 - para un ejército que se achicó en casi un $50 \%$. Además FAES es el 
único órgano del Estado cuyo presupuesto no está sometido a control civil; se mantienen las partidas secretas manejadas a discreción del comandante en jefe. Persiste tambiến la cláusula constitucional que autoriza al presidente a desplegar a la FAES «para el mantenimiento de la paz interna, la tranquilidad y la seguridad públican ${ }^{1}$. En función de esta disposición que preserva para la FAES funciones que según los acuerdos son privativas de la PNC, a fines de 1994 la FAES estaba desplegada en 14 puntos del territorio nacional. En noviembre de ese año la FAES participó en la represión violenta de una protesta laboral cerca de la frontera con Honduras, con el saldo de tres muertos. En febreto de 1995 el gobierno destinó a unos 6 mil miembros de la FAES para patrullar militarmente las zonas rurales del país ante el auge de la delincuencia. La decisión fue criticada por el FMLN, Convergencia Dernocrática y el Partido Demócrata Cristiano porque violaba los acuerdos de paz en cuanto volvía a asignar a la FAES funciones policiales, pero fue celebrada por la Asociación Nacional de la Empresa Privada (ANEP) que agrupa a los más grandes empresarios. De acuerdo con numerosos observadores independientes, la FAES continuaría desempeñando funciones de inteligencia, también en violación de los acuerdos. En general, las resistencias de la FAES a una completa desmilitarización contrastan con el rápido proceso de reconversión del FMLN en una organización civil.

\section{Seguridad pública}

Se registra una sensible mejoría, pero la situación está lejos de ser satisfactoria. Según algunas encuestas de opinión, la delincuencia es el problema más grave de El Salvador, seguido por el desempleo y la corrupción gubernamen$\mathrm{tal}^{2}$. La disminución de la violencia motivada por causas políticas no ha sido acompańada de una reducción equivalente de la delincuencia "común»: asaltos a comercios, a residencias particulares y a medios de transporte; actos de violencia cometidos por pandillas (maras); secuestros con fines de rescate, y otros. Todo ello favorecido por la existencia de armas en poder de grupos civiles e individuos, a pesar de las campañas de desarme organizadas por el gobierno con el apoyo de ONUSAL.

Existen evidencias que permiten afirmar que los escuadrones de la muerte siguen operando. A fines de 1993 los escuadrones asesinaron a varios dirigentes del FMLN y atentaron contra otros. Después de firmes presiones del secretario general de la ONU y de la comunidad internacional, el gobierno de ARENA presidido por Alfredo Cristiani aceptó las demandas de amplios sectores de la sociedad, de investigación y castigo de esos hechos. Sin embargo, las recomendaciones de la comisión investigadora, que actuó sometida a múltiples limitaciones, no fueron cumplidas por el gobierno de ARENA ahora presidido por Armando Calderón Sol. El informe de la comisión señala una metamorfosis de los escuadrones en su estructura, funcionamiento y objeti-

1. Artículo 168 inc. 12.

2. Cf. por ejemplo Universidad Tecnológica, VII Encuesta de Opinión Páblica. 100 dias de gobierno del Dr. Armando Calderón Sol. San Salvador, setiembre de 1994. 
vos. Actualmente operarían de manera descentralizada sin la coordinación del pasado; sus "áreas de trabajo" incluyen asaltos a bancos, secuestros con fines pecuniarios y narcotráfico ${ }^{3}$.

La hipótesis de que se mantienen vínculos personales entre miembros de la FAES y los escuadrones es avalada por algunos hechos particularmente graves. En junio de 1994 un grupo portando armas militares, algunos de sus miembros vistiendo uniformes de la Policía Nacional, robó en pleno día casi un cuarto de millón de dolares de un banco en el centro de San Salvador; en el hecho murieron varias personas. Poco después se descubrió que el operativo fue dirigido por un teniente de la FAES, jefe de Investigaciones de la Policía Nacional. El oficial fue detenido poco después, pero en fébrero de 1995 fue dejado en libertad. El dinero del robo (alrededor de 200 millones de colones) nunca fue recuperado.

La nueva Policía Nacional Civil (PNC) completó su despliegue en todo el territorio; el entrenamicnto de sus miembros está a cargo de la nueva Academia Nacional de Seguridad Pública (ANSP), que cuenta con asesoramiento de las policías de los Estados Unidos, Suecia, España y otras. Ia PNC debía integrarse con el $20 \%$ de ex miembros del FMLN, el $20 \%$ de ex FAES y el $60 \%$ de candidatos civiles. Debido a que el FMLN no pudo completar su cuota, aumentó el número de candidatos "civiles"; algunos asesores extranjeros de la ANSP sospechan que muchos de estos son en realidad ex miembros de la FAES e incluso de la vieja Polića Nacional. Comparada con ésta, y con sus colegas de Centroamérica, la nueva PNC muestra hasta ahora un desempeño superior, aunque ha estado sometida a frecuentes denuncias de violación a los derechos humanos ${ }^{4}$. Esto puede deberse tanto a las deficiencias en la formación de la PNC y a la persistencia de estilos autoritarios en su desempeño, como a la existencia de un clima institucional para que la población formule denuncias sin temor a represalias.

\section{Derechos humanos y poder judicial}

Los informes periódicos de la División de Derechos Humanos de ONUSAL (DHONUSAL) señalan un avance sensible en este terreno; mis entrevistas sugieren en cambio un panorama menos definido, aunque coinciden en que el contraste con la época de la guerra es notorio ${ }^{5}$. En marzo de 1992 una ley de la Asamblea Legislativa creó la Procuraduría para la Defensa de los Derechos Humanos (PDH). Sus recursos son insuficientes y sus recomendaciones fre-

3. Informe del Grupo Conjunto para la inuestigacion de grupos armados ilegales con motivacion politica. San Salvador, 28 de julio de 1994. La situación de los escuadrones de la muerte en EJ Salvador es parecida a la de la llamada umano de obra ociosan de los grupos parapoliciales y paramilitares en Argentina en los inicios de la ctapa postictatorial.

4. Véase DHONUSAL, $\mathrm{X}$ y XI Informe del Director de la División de Derechos Humanos al Secretario General, 1993 y 1994.

5. Véase también el editorial «Violencia inscicucionalizada». En ECA, Estudios Centroamericanos, núm. 549, p. 615-628, julio de 1994. 
cuentemente chocan con la falta de respuesta de los órganos del Estado que deberian cumplirlas. Se ha avanzado mucho más en materia de denuncia de violaciones - cuestión en la que existe una amplia y trágica experiencia acumulada- que en materia de protección, promoción y resolución de casos.

La creación de una Subprocuraduría para los Derechos de la Mujer y la Nińez marca un punto de inflexión respecto de la invisibilidad institucional de la mujer, sus derechos y las múltiples formas de discriminación en la sociedad salvadoreña. Junto a otras reformas institucionales, como la creación de los tribunales de familia (muchos de cuyos integrantes son mujeres) y la sanción de un código de familia, la creación de la Subprocuraduría abre expectativas de mejoramiento de una de las áreas más vulnerables de la situación de los derechos humanos y del proceso de democratización. Sin embargo, el tema de la mujer sigue vinculado a los enfoques tradicionales que ligan a la mujer a la problemática de la familia y la infancia.

Las demoras en la depuración y reforma del poder judicial y la legislación crean obstáculos adicionales a una plena vigencia de los derechos humanos; la violación al debido proceso legal se ha explicitado como uno de los aspectos más graves. Entre junio de 1992 y junio de 1994 nadie fue condenado judicialmente por alguno de los 75 casos más graves de violaciones al derecho a la vida, denunciados por DHONUSAL. El nombramiento de una nueva Corte Suprema de Justicia en julio de 1994 tras difíciles negociaciones permite abrigar expectativas de progresos en este terreno. Pero cuando en noviembre DHONUSAL entregó a la Corte una lista de 50 jueces acusados de corrupción y mal desempeño, el presidente Calderón Sol denunció a DHONUSAL por intervenir en asuntos internos del país; una actitud que pone dudas sobre el interés real del gobierno en avanzar en este terreno. En todo caso, la lista parece haber quedado engavetada. Este conjunto de factores justifican la afirmación del FMLN y de las organizaciones de defensa de los derechos humanos, de que se mantiene la impunidad.

\section{Democratización}

Las elecciones de marzo pasado futeron las más democráticas de la historia política salvadoreña. A pesar que sus resultados defraudaron las expectativas en una victoria de la adianza Convergencia Democrática/FMLN, por primera vez. fue posible una oposición real y los resultados fueron respetados. Las denuncias respecto de dificultades en la inscripción de los votantes en las zonas de guerra, y limitaciones a una competencia plena entre partidos no invalidan los resultados. Por primera vez El Salvador cuenta con un parlamento que refleja a todas las corrientes políticas ${ }^{6}$.

6. Vease SPENCE, Jack y otros., El Salvador: Elections of the Century. Cambridge, Ma.: Hernisphere Initiatives, julio de 1994. También CORDOVA MACtAS, Ricardo "El Salvador en transicion: El proceso de paz, las elecciones de 1994 y los retos, de la gobernabilidad democrática». Fundación Ungo, Documentos de Trabajo, San Salvador, 1994. 
Además de ingeniería institucional (reformas legales), la democratización de El Salvador demanda cambios profundos en la cultura política de autoritarismo de las elites y de sectores amplios de la población. En este aspecto se ha avanzado mucho menos que en el primero. Se ha alcanzado un clima de tolerancia entre partidos políticos y corrientes de opinión que coexiste empero con un ambiente de inseguridad pública. La competirividad politica institucional convive con desigualdades sociales profundas que cuestionan la vigencia efectiva de los derechos de ciudadania y configuran un escenario que se parece mucho al de la etapa anterior al conflicto militar. Además, la tolerancia se refiere hasta ahora mucho más a las relaciones entre las elites políticas que a las relaciones entre éstas y la gente que vive en la pobreza o carece de la integración estable en el sistema económico social. Este desnivel entre una democratización de "los de arriba" y otra, mucho menos desarrollada, de "los de abajon, habria jugado un papel en el coeficiente de abstención de las elecciones de marzo, que alcanzó el $40 \%$ de los votantes potenciales.

\section{Transferencia de tierras y programas de reinserción}

Aquí se registran los mayores atrasos en el cumplimiento de los acuerdos. El programa de transferencia de tierras se estancó y seguía inconcluso en mayo de 1995; según funcionarios de la USAID, básicamente por falta de voluntad del gobierno -opinión que coincide con la del FMLN. Hacia principios de 1995 sólo el $31 \%$ de los excombatientes y bases del FMLN, y el $25 \%$ de ex miembros de la FAES, consiguieron tierras: en conjunto menos de 12.000 beneficiarios sobre un total de más de 47.000 . Esta siruación alimenta la frustración de los ex combatientes de uno y otro bando. Además, los pocos que consiguen tierra deben experimentar limitaciones en materia de crédito, asistencia técnica y capaciración; el tamaño reducido de las parcelas y la falta de apoyo financiero e institucional dificultan las posibilidades de desarrollar una actividad productiva sustentable. Muchos abandonan las parcelas y engrosan las filas de los migrantes a Estados Unidos. De acuerdo con el FMLN, en febrero de 1995 todavía faltaba adjudicar tierra a 12.888 ex combatientes, es decir el $47 \%$ de los beneficios potenciales.

Las políticas gubernamentales no prestan casi ninguna atención a este problema. La situación de los ex combatientes es casi tan invisible como la de las mujeres, lo cual hace más dramática aún la situación de las mujeres ex combatientes. Esta misma invisibilidad se verifica en los organismos internacionales. De las 16 recomendaciones del Socioeconomic Report del Inter American Development Bank solamente una se refiere (en apenas seis líneas) a la cuestión de la tierra (como parte de la reforma administrativa) y ninguna a la cuestión del empleo ${ }^{7}$. Igual desatención se advierte en el informe del Banco Mundial sobre pobrezas.

7. IADB, Socioeconomic Report: El Salvador. GN-1800, Junio 1993, p. 3-13.

8. WORLD BANK. El Salvador. The Challenge of Poverty Alleviation. Report 12315-ES, junio de 1993. 
En síntesis, el cumplimiento de los acuerdos está más avanzado en materia de paz que de democracia; en desmilitarización que en vigencia de derechos humanos y cese de la inseguridad y la impunidad; en reformas institucionales más que en cuestiones económicas y sociales. Con todas sus limitaciones, los avances son resultado de las presiones del FMLN y del respaldo de la comunidad internacional, mucho más que de la colaboración del gobierno de El Salvador. Tanto durante la presidencia de Alfredo Cristiani, como en la actual de Calderón Sol, la retórica official no alcanza a ocultar la resistencia de ARENA y de las elites empresariales a un cabal cumplimiento de los acuerdos. La amplia amnistía concedida por Cristiani a todos los militares que la Comisión de la Verdad responsabilizó por violaciones a los derechos humanos refleja bien la posición de ARENA y los sectores militares y empresariales que representa?.

Se registra una distancia enorme entre los acuerdos de paz y las políticas económicas y sociales del gobierno. Los enfoques macroeconómicos de éstas dificultan adicionalmente el cumplimiento de aquéllos; esos enfoques implican definiciones estratégicas y de política adoptados antes de la firma de los acuerdos - reducción del gasto público, privatizaciones, desregulaciones, sistema tributario regresivo, adopción de criterios eficientistas que marginan a sectores amplios de la pequeña y mediana producción, poca generación de empleo, etc.- $y$ que el gobierno actual intenta profundizar. El aporte de fondos gubernamentales al proceso de paz y democratización es mínimo, lo cual incrementa la dependencia de la cooperación internacional; a medida que el tiempo pasa ésta tiende a disminuir. Los programas inspirados en los acuerdos se encuentran desfinanciados, y los compromisos asumidos por el gobierno de El Salvador con las agencias financieras internacionales dificultan aún más el cumplimiento de los acuerdos ${ }^{10}$. La reforma impositiva del gobierno de Alfredo Cristiani, de acuerdo con las recomendaciones de esas agencias, eliminó el impuesto al patrimonio e introdujo el IVA, acentuando una regresividad del sistema tributario que beneficia notoriamente a las elites económicas representadas en el gobierno de ARENA.

\section{El contexto socioeconómico}

El conflicto político-militar que asoló a El Salvador durante la década de 1980 tuvo impactos severos en la economía y abrió profundas heridas en el tejido social; efectos que se acumularon a los provocados por la crisis económica regional y por el previo deterioro de los mecanismos de integración regional. Las zonas de guerra cubrieron el $40 \%$ de la superficie nacional con el $20 \%$ de la población. Las víctimas de la guerra y de la contrainsurgencia se conjeturan

9. NACIONES UNIDAS. De la locura a la esperanza. La guerra de 12 años en El Salvador. Informe de la Comisión de la Verdad para EI Salvador. San Salvador/Nueva York, 15 de marzo de 1993.

10. Véase: Soto, Alvaro DE; CASTlllo, Graciana DEL, "Obstacles to Peacebuilding", Foreign Policy, núm. 94, p. 69-83. (primaveta de 1994). 
en 75.000 personas - muchas de ellas en circunstancias atroces-, a las que deben agregarse centenas de miles de emigrados y desplazados. Entre $198 \mathrm{I}$ y 1990 el producto por habitante acumuló una caída de más del $15 \%$, el valor (FOB) de las exportaciones se redujo más del $50 \%$ y el balance comercial acumuló un saldo negativo de más de unos 3.000 millones. El deterioro de la infraestructura económica y social fue muy grande, en un país donde ésta ya presentaba, antes del conflicto, serias insuficiencias.

Durante ese lapso la economía salvadoreña subsistió merced a un abundante flujo de donaciones oficiales y de las remesas de los emigrados. Durante la década pasada El Salvador recibió del gobierno de Estados Unidos 3.919,3 millones de dólares en ayuda al desarrollo y de asistencia militar: un promedio de 357 millones por año. A esto se sumaron casi 315 millones, de ayuda oficial al desarrollo proveniente de Europa, Canadá y Japón e inversión extranjera directa. Las remesas familiares sumaron 3.366,7 millones de dólares en 19801989 (un promedio anual de 337 millones), y subieron a 2.420 millones en 1990-1993 (605 millones de promedio anual); en el primer semestre de 1994 sumaron casi 470 millones. Además de constiruir la fuente principal de subsistencia para alrededor de un tercio de los hogares, las remesas son el factor que en los años recientes ha permitido equilibrar la balanza de pagos del país. Tomando en cuenta solamente la década de 1980, El Salvador recibió en concepto de remesas y dotaciones oficiales más de 7.600 millones de dólares, suma superior al total agregado de los ingresos de exportación en el mismo período (poco más de 7.500 millones).

\section{Desempeño reciente de la economia}

La reducción de la guerra desde 1990 y los acuerdos de paz de 1992 cambiaron el escenario institucional y crearon condiciones para la recuperación del crecimiento y la reactivación de la inversión. Un programa amplio de reformas financieras y fiscales cambió los parámetros institucionales de la actividad gubernamental y de la iniciativa privada. Se unificó el tipo de cambio y se liberalizó el mercado de divisas, se eliminaron los permisos de importación y los depósitos previos, se redujeron sensiblemente los derechos de importación, se eliminaron las exenciones arancelarias y se simplificaron los procedimientos de importación y exportación. Se llevó a cabo una reforma tributaria que simplificó los instrumentos y procedimientos de recaudación. Se redujo drásticamente el número de artículos sometido a control de precios y se puso fin al monopolio estatal de la comercialización del café y el azúcar. Se dio autonomía al Banco Centrał de Reservas, se adoptó una política de severa disciplina fiscal y se privatizó la banca comercial.

La economía salvadoreña muestra signos de reactivación en los años recientes, aunque es dificil discernir cuanta reactivación es resultado de las reformas y cuanta del fin de la guerra. En 1991-1994 el PIB acumuló un crecimiento del $18,3 \%$ y el PIB por habitante el $9,6 \%$, en ambos casos superior al promedio de Centroamérica. Las mayores tasas de crecimiento se registraron en la cons- 
trucción, la industria manufacturera y los servicios básicos, mientras agricultura, que contribuye con más del $25 \%$ del producto, mostró un comportamiento con alzas y bajas, especialmente la de consumo interno. En el último bienio los sectores de bienes no transables (construcción, finanzas) apuntan como los de mayor dinamismo, situación que contradice los esfuerzos de los programas gubernamentales y de las agencias financieras multilaterales. El coeficiente de inversiones creció respecto de la década pasada, pero en el bienio 1992-1993 se estabilizó en torno a algo más del $16 \%$ del PIB. La relación inversión pri$\mathrm{vada/inversión} \mathrm{pública} \mathrm{se} \mathrm{mantuvo} \mathrm{3:1} \mathrm{durante} \mathrm{el} \mathrm{último} \mathrm{quinquenio.}$

El valor de las exportaciones creció en los túltimos cinco años a ritmo menor que el valor de las importaciones, con lo que se generó una brecha comercial que acumuló un déficit de más de unos 2.125 millones ał año en 1991-1993. El auge reciente de los precios del café contendrá en lo inmediato esta tendencia deficitaria y aiterará coyunturalmente el peso de las exportaciones tradicionales (café, algodón, azúcar y camarones) en las ventas externas en detrimento de las no tradicionales; éstas representan hasta ahora alrededor de dos tercios del total, con un peso fuerte de textiles. La liberación del comercio exterior a partir de las reformas antes mencionadas impactó más en el crecimiento de las importaciones que en el de las exportaciones - para lo cual las reformas fiscales son insuficientes. En el cuatrienio 1991-1994 las importaciones crecieron a un ritmo promedio de casi el $15 \%$, casi el doble que las exportaciones.

El balance de la cuenta corriente acumuló saldos negativos por unos 1.452 millones en 1991-1994, compensados por un movimiento neto de capitales de casi unos 1.700 millones. El endeudamiento externo no adquirió en $\mathrm{El}$ Salvador la magnitud de otros países de la región, como Nicaragua o Costa Rica; en 1990 la deuda externa total desembolsada sumó unos 2.200 millones y subió a poco más de unos 2.330 millones en 1992. En este año tuvo lugar una condonación de unos 464 millones y el Banco Central de Reservas cancelb́ algunos compromisos, con lo que en 1993 el monto total del endeudamiento externo se situó en unos 1.938 millones y se mantuvo prácticamente en ese mismo nivel en 1994. Este último año el ingreso de divisas por donaciones oficiales y remesas de familiares fue suficiente para cubrir importaciones, para el pago del servicio de la deuda y para mantener el nivel de las reservas internacionales.

Las reformas económicas introducidas desde 1990 tuvieron un impacto inicial favorable en el nivel general de precios en cuanto redujeron el déficit fiscal, pero en 1993 la inflación volvió a acelerarse; el índice general creció el $18,6 \%$ en contraste con el descenso del $24 \%$ al $11,2 \%$ que había experimentado en el trienio 1990-1992. La afluencia de divisas de libre convertibilidad por las donaciones destinadas al proceso de paz, y las remesas de familiares, frente a la menor reactivación de la oferta de bienes y al mantenimiento del tipo fijo de cambio, provocaron el alza del nivel de precios. Debe destacarse que el incremento del índice de precios de los alimentos entre 1992 y 1993 fue casi el doble que el aumento del índice general, en tanto que entre 1990 y 1992 la reducción 
del índice de precios de los alimentos fue menor que la del índice general. Mientras en 1993 el índice general de precios se mantenía un tercio por debajo del nivel de 1990, el índice de alimentos había recuperado el nivel del primer año. Es ésta una situación que afecta particularmente a los grupos de menores ingresos, que son también los más golpeados por el conflicto reciente ${ }^{11}$.

Durante 1993 se registró una tímida recuperación de las remuneraciones reales, después del trienio 1990-1992 de signo sistemáticamente negativo. El salario mínimo real agropecuario creció el $3,8 \%$ después de acumular una caída del 18,3\% en 1990-1992. El alza del año pasado es insuficiente para compensar la tendencia negativa de los años recientes (reducciones reales del 33\% en café, el $15 \%$ en azúcar, el $10 \%$ en algodón y entre el $14 \%$ y el $23 \%$ en agroindustrias) e impide augurar una reversión de la misma. Los salarios urbanos (industria manufacturera y comercio) registraron una evolución negativa menos marcada que los del sector agropecuario y de agroindustrias. Debe destacarse asimismo que en solo dos ramas de la economía (minería y finanzas) los salarios promedio alcanzan a cubrir el costo de la canasta básica familiar alimenticia (2.100 colones, equivale a la línea de pobreza absoluta o crítica) ${ }^{12}$.

\section{Pobreza y exclusión social}

La tasa de desocupación creció entre 1991 y mediados de 1994, pero más en el campo que en las ciudades. A mediados de 1994 el desempleo abierto total registró una tasa de $9,5 \%$ de la $\mathrm{PEA}$, de $7,5 \%$ en el área urbana y de $12,4 \%$ en el campo. En cconomías como la salvadoreña, con mercados de trabajo imperfectos y sistemas muy precarios de seguridad social, la tasa de desempleo abierto ofrece un panorama incompleto de la subutilización efectiva de la fuerza de trabajo. Sólo dos tercios de los ocupados urbanos lo están plenamente, mientras el resto está subocupado. Sumando desempleo abierto y subempleo se alcanza, a mediados de 1994, una tasa de subutilización de la mano de obra urbana de $41,7 \%$ de la PEA. Una proporción alta del emplco total se desenvuelve en pequeños establecimientos en condiciones precarias de empleo y remuneración; alrededor de la mitad de la PEA urbana pertenece al lilamado sector informal urbano con elevados niveles de subutilización de la fuerza de trabajo. Las mujeres representan casi dos tercios de la población subempleada.

La distribución del ingreso continúa siendo profundamente desigual. En 1990 en $20 \%$ inferior de los hogares percibia el 3,9\% del ingreso familiar total, mientras el $20 \%$ superior percibía el $50,3 \%$, es decir, una proporción casi trece veces mayor ${ }^{13}$. Desde entonces la situación se ha mantenido sin cambios significativos: a mediados de 1994 el $20 \%$ inferior captaba el $4 \%$ del ingreso

11. Cifras preliminares para 1994 indican una nueva reducción en el ritmo de crecimienro del indice general de precios.

12. Friedrich Ebert Stiftung. El Salvador. Informe Laboral 1994, núm. 2 (abril de 1995), San Salvador.

13. IADB, op. cir, Apendice Estadistico, cuadro V-4. 
total, y el $20 \%$ superior el $49,5 \%^{14}$. Similarmente graves son los indicadores de pobreza aunque estos varían en función de las diferentes metodologías. De acuerdo con la CEPAL el $71 \%$ de la población salvadoreńa se encontraba en condiciones de pobreza en 1990: el 61\% en las áreas urbanas y el $85 \%$ en las rurales ${ }^{15}$. La Encuesta de Hogares detectó el $57,5 \%$ de hogares en condiciones de pobreza en 1992-1993: el 30,5\% en condiciones de pobreza relativa y el $27 \%$ en pobreza extrema; a mediados de 1994 esos registros fueron del $52,8 \%$ de población en condiciones de pobreza, con $29,6 \%$ en pobreza relativa y 23,2\% en pobreza extrema. Por su parte, el Banco Mundial calculó en 1992, aplicando la metodología combinada de línea de pobreza y necesidades básicas, el $68,4 \%$ de pobres $(55,3 \% \text { en las ciudades y } 87,8 \% \text { en las áreas rurales })^{16}$. La guerra impactó severamente en las condiciones de vida de muchos salvadoreños, pero los altos niveles de pobreza no son principalmente imputables al conflicto; ya en 1980 CEPAL calculó que el $68 \%$ de la población total de El Salvador, y el $76 \%$ de la población rural, se encontraba en condiciones de pobreza.

I a amplia variación de las estimaciones y los cálculos de la población en condiciones de pobreza producidas por diferentes organismos obedece a la utilización de metodologías diversas: línea de pobreza, insatisfacción de necesidades básicas, y otras. La magnitud que en todos los cálculos asumen los resultados respectivos indica, sin perjuicio de las diferencias, una coincidencia en señalar la existencia de una situación insatisfactoria y preocupante desde todo punto de vista. Una discusión técnica de los alcances y limitaciones de cada metodología excede los alcances de esta presentación ${ }^{17}$.

La dificultad en el acceso a la información sistemática y en particular la falta de series y la reducida comparabilidad de los estudios puntuales por las razones señaladas más arriba, obliga a que la discusión sobre el signo de la evolución de la pobreza en el período posterior a los acuerdos (1990-1994) deba conjugar datos, hipótesis y corazonadas - sin que siempre sea posible distinguir nítidamente unos de otras. No existen elementos plausibles de juicio para afirmar un deterioro adicional de la situación - de hecho, su propia magnitud hace que su evolución incluso en términos negativos sea lenta-, pero tampoco se cuenta con evidencias firmes de una mejoría sustantiva -que, en todo caso, es función de factores que no operan en el corto plazo. Los estudios más recientes sobre este tema coinciden en afirmar la existencia de una relación de causalidad entre desigualdad y pobreza: el crecimiento de la pobreza en América latina sería ante todo, desde esta perspectiva, una función de la creciente desigualdad social, que define una inequitativa distribución de ganadores y perdedores, tanto en momentos de recuperación y auge como en

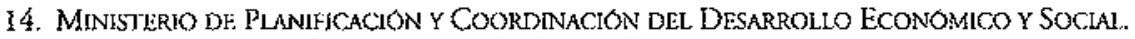
Encuesta de Hogares de Propbsitos Múltiples 1994.

15. CEPAL, Bases para la transformación productiva y generacion de ingresos de la población pobre de los patses del istmo centroameriano. LC/Mex/G3Rev, 2, 6 de eneto de 1992.

16. WORID BANK. El Salvador. The Challenge of Poverty Alleviation, cir.

17. Véase, por ejemplo, BolTviNiK, Julio. "La medición de la pobreza en América latina". Comercio Exterior, núm. 41 (5), p. 423-428, mayo de 1991. 
momentos de estancamiento y recesión ${ }^{18}$. En esta línea de razonamicnto, podría conjeturarse que el mantenimiento de una fuerte polarización social $\mathrm{y}$ de niveles altos de población en condición de pobreza, incrementa en valores absolutos simplemente por efecto del crecimiento demográfico, y constantes otros factores, el número de pobres. Se insiste en que este razonamiento no tiene más valor que una conjetura a partir de la cual podrían definirse hipótesis más precisas.

La alta proporción de población en condiciones de pobreza, la reducida eficacia de la estrategia cconómica adoptada por el gobierno salvadoreño para encarar la cuestión y el avance lento de los programas de reinserción económica y transferencia de tierra mantienen la migración hacia el exterior y las remesas de familiares como mecanismos de respuesta adaptativa de varios centenares de miles de salvadoreños a la situación presente y su probable evolución. Las remesas llegan en pequeñas sumas; son aplicadas sobre todo al consumo familiar y el mejoramiento de la vivienda. En 1992 y 1993 las remesas sumaron el $14 \%$ más que el valor de las exportaciones y representaron más del $10 \%$ del PIB. Estas cifras avalan la hipótesis que migración y remesas constituyen no sólo microestrategias de sobrevivencia para alrededor de un tercio de las familias salvadoreñas, sino también un ingrediente contabilizado por el gobierno salvadoreño y por las agencias financieras multilaterales en sus diseños mactoeconómicos. Proyecciones elaboradas por el FMI y el Banco Central estiman que las remesas continuarán en ascenso, en la medida que los factores que estimulan la migracion externa sigan vigentes y que el gobierno de Estados Unidos no altere sensiblemente las condiciones de ingreso y trabajo de los migrantes - en particular la política de concesión de permisos temporales de trabajo y el tratamiento de los inmigrantes ilegales.

\section{Realineaciones en el terreno de la política}

Las elecciones generales de 1994 explicitaron las transformaciones políticas experimentadas en los años finales de la guerra y dieron cauce a la participación del FMLN. La relevancia de estos comicios deriva no solamente de la aritmética electoral, sino asimismo del nuevo escenario institucional que contribuyeron a diseñar. Sin perjuicio de irregularidades en el proceso de registro de los electores ${ }^{19}$, todos los participantes aceptaron el veredicto de las urnas. ARENA se impuso pero sólo en la segunda vuelta, situación que marcó un contraste con su triunfo en 1989 en la primera ronda; con algo más de 641.000 votos (49\%), aumentó su caudal en casi 136.000 respecto de 1989. Por su lado la coalición FMLN-Convergencia Democrática-MNR sumó casi 326.000

18. Vuskonç, Pedro Pobreza y desigualdad en América latina. México: Centro de Investigaciones Interdisciplinarias en Humanidades, UNAM, 1993; Al:TiMIR, Oscar "Cambios en la desigualdad y la pobreza en América Latinan. El Trimestre Económico, núm. 24, p. $85-133$ (eneromarzo de 1994).

19. Véase Cordova Macfas, op. cit., 28 y s. 
votos en la primera vuelta $(24,9 \%)$, mientras el Partido Demócrata Cristiano (PDC) sumó algo más de 214.000 (16,4\%), con una pérdida de 124.000 votos respecto de 1989. En total se contaron 1,3 millón de votos, lo que indica que se mantiene la pauta de alta abstención (52\% respecto del padrón total, o 44\% de los que contaban con carnet electoral).

Incorporado plenamente al nuevo escenario institucional, el FMLN explicitó en él las tensiones y los conflictos que lo cruzaban desde la etapa del conflicto. La separación de ERP y RN en diciembre de 1994, poco antes de la Convención Nacional del FMLN, culminó un proceso en cuyo desarrollo se hizo evidente la falta de interés de elementos directivos de esas dos organizaciones en una democratización profunda y en transformaciones sociales de signo popular. En particular culminó un proceso de enfrentamiento de Joaquín Villalobos con la insistencia del FMLN en demandas de cambio social. Curiosamente, la autodefinición de Villalobos como "socialdemócrata" involucró un desentendimiento respecto de las dimensiones sociales de la democratización y con los programas respectivos de los acuerdos de paz: transferencia de tierras, reinserción económica de los ex combatientes, reformas sociales. Esa autodefinicion, sin embargo, le permitió aproximarse al diminuto Movimiento Nacionalista Revolucionario (MNR) que en las últimas elecciones obtuvo un modesto $9,4 \%$ de los votos y ningún asiento en la Asamblea Legislativa, pero conserva membresía en la Internacional Socialista.

Sancho y Villalobos explicaron su ruptura como producto de una redefinición ideológica: dejar de lado el doctrinarismo y el autoritarismo de la izquierda militarista de las otras tres organizaciones, y meterse de lleno en un estilo supuestamente más moderno de hacer política. Sus ex aliados del FMLN rechazan la imputación de militarismo; de lo que se trata, afirman, es de honestidad y consistencia con las demandas populares y con una democratización verdadera. En todo caso, la autoproclamada vocación democrática de los disidentes no impidió que RN tratara de expulsar a Eduardo Chicás cuando éste decidió alinearse con la mayoría del FMLN, o que Villalobos apelara a acusaciones casi policíacas para desacreditar a las FPL y al FMLN. Después que en setiembre de 1994 un grupo de desmovilizados de la FAES ocupó con violencia la sede de la Asamblea Legislativa, Villalobos acusó a las FPL de haber tramado el operativo para desestabilizar el proceso de democratización. Las FPL y el FMLN rechazaron la imputación. Villalobos trató de defenderse alegando que el operativo hab́a sido decidido en una reunión de la dirección del FMLN, pero la explicación fue peor que la acusación: desde varios meses antes Villalobos y Sancho habían sido suspendidos de dicha conducción por motivos de indisciplina y no participaban de esas reuniones ${ }^{20}$.

20. A mismo riempo, los diputados de la ERP y RN han bloqueado algunas denuncias de corrupción contra miembros de ARENA. Por ejemplo, se opusieron a que se investigaran denuncias, aparentemente avaladas por documentos oficiales, concra Olga Salguero de Gross, presidenta de la Asamblea I,egislativa, miembro prominente de ARENA, y públicamente sospechada de haber apoyado a los escuadrones de la muerte en la década de 1980. 
La ruptura de ERP aceleró la fractura interna de ambas organizaciones. La escisión se efectivizó antes de la convención del FMLN, circunstancia que algunos observadores explican por el interés de Villalobos y Sancho de zafarse de una discusión de sus posiciones en un ambiente previsiblemente poco amistoso. Es llamativa la insistencia de Villalobos en reclamar la disolución del FMLN por haber agotado, a su juicio, su misión histórica. Junto con el pequeño MNR, ERP y RN constituyeron la Iniciativa Socialdemócrata (ISD), que al poco tiempo cedió paso a su denominación actual: Partido Demócrata. Un cambio de nombre en el que parece haber incidido la desconfianza suscitada en el seno de la Internacional Socialista, y el interés demostrado por elementos del Partido Demócrata de Estados Unidos en el viraje proclamado por Villalobos. En la medida en que FPL, PRTC y PCES son las organizaciones del FMLN que en estos tres años participaron más activamente en la ejecución de los acuerdos y en las presiones sobre el gobierno de El Salvador, la salida de los elementos de ERP y RN no tuvo impacto en este terreno. Es difícil no pensar que los acuerdos nunca ocuparon el centro de los intereses de ERP y RN.

En junio de 1995 el Partido Demórata, ARENA y el gobierno presidido por Armando Calderón Sol firmaron el pacto de San Andrés, propuesto por el primero, el cual implicó la institucionalización de la alianza de los ex guerrilleros con el gobierno de ARENA, en los términos de ARENA. Aunque la letra del acuerdo incluye un conjunto amplio de reformas institucionales y de políticas, la incapacidad del nuevo PD de llevarlas a cabo deja como único hecho sustantivo del pacto la adhesión apendicular del PD a la conducción política de la extrema derecha salvadoreña ${ }^{21}$.

Por su lado el FMLN emergió de la Convención como un partido "de tendencias", vale decir, en el que las tres organizaciones que se mantienen dentro de él -.FPL, PCES Y PRTC - - y las escisiones de ERP y RN, ingresan en un proceso de progresiva indiferenciación, manteniéndose como "tendencias" de opinión más que como organizaciones individuales. Salvador Sánchez Cerén ("Leonel González") resultó electo coordinador tras la decisión de Shafik Handal de no optar a la reelección. Eduardo Chicás, de la fracción de RN quue decidió mantenerse dentro del FMLN, fue elegido vicecoordinador adjunto. Con posterioridad a la Convención y en ejecución de sus resoluciones, las tres organizaciones decidieron sus respectivas disoluciones.

La ruprura en el FMLN es un ingrediente de la crisis por la que atraviesa la totalidad de las organizaciones políticas salvadoreñas; todas ellas están pasando por severas tensiones en la difícil transición de un escenario de dictadura y fraude electoral sistemático primero, y de contrainsurgencia y guerra después, a otro de paz y democratización. Ya se hizo referencia al severo retroceso electoral del MNR. La Democracia Cristiana también fue duramente

21. Una extrema derecha que no ha moderado para nada su extrcmismo doctrinario. Los Principios, Objetivos y Estatutos de ARENA siguen afirmando, como primer objetivo "Defender nuestras tradiciones occidentales ante el ataque ideológico y agresión permanente del comunismo internacional [...]». 
golpeada. En las elecciones de marzo obtuvo un modesto $16 \%$ de los votos, como resultado de una fuga de votos reformistas hacia la opción de izquierda representada por la alianza CD-FMLN-MNR, que apoyó a la candidatura presidencial de Rubén Zamora; con más del $21 \%$ de los votos, la izquierda se convirtió en la segunda fuerza electoral.

La crisis se ha instalado asimismo en ARENA, entre el grupo del ex presidente Cristiani (la "argolla dorada») y el que se nuclea en torno al presidente Calderón Sol. La privatización de los bancos durante el gobierno de Alfredo Cristiani (1989-1994) es considerado el "acto fundante" del nuevo grupo de poder de Cristiani, cuyos miembros se repartieron las instituciones entre ellos, incluyendo al propio Cristiani, que era en esa época presidente de la república 22 . Los grupos empresariales y militares marginados del negocio vieron en Calderón Sol la posibilidad de conseguir algo en compensación, pero sus expectativas resultaron nuevamente frustradas: a pesar de su trayectoria partidaria diferenciada de la de Cristiani, Calderón no puede enfrentarse a éste y debe convivir con la "argolla de oro". Se escenifica así dentro de ARENA un doble conflicto: 1) entre la "argolla de oro" y los desplazados por elia; 2) entre el equipo más íntimo de Calderón Sol y los elementos de su gobierno más vinculados al poder económico empresarial, cuyo principal representante era el vicepresidente Eduardo Borgo Bustamente ${ }^{23}$.

El grupo de Calderón está formado por varios de los polfticos y empresarios que se separaron de ARENA después que, en las elecciones de 1984, su candidato presidencial el ex mayor Roberto D'Abuisson fue derrotado por el demócrata cristiano José Napoleón Duarte ${ }^{24}$. En aquel momento la escisión

22. Véase SORTO, Francisco; SEgovin, Alexander "Hacia dónde se dirige la privatización de la banca?". Revista Politica Económica, núm. 12, 1992 (San Salvador: CENITEC). De acuerdo con mis entrevistas, Alfredo Cristiani desplegó una activa vida empresarial durante su mandato presidencial. Además de haberse beneficiado con la privatización bancaria (se convirtió en el principal propietario del Banco Cuscattán, uno de los tres más grandes) su droguería "Santa Lucía" se benefició de importantes contratos de importación de medicinas en los años de la guerra, mientras que buena parte de los viajes oficiales de la época fueron tramitados por su propia empresa turística. Su empresa aseguradora "CISA" contrataba una porción grande de los seguros del secror público, mientras que los entes descentralizados (en las áteas de telecomunicaciones, energia y otras) depositaban sus fondos en cuentas de cheques del Banco Cuscatlán que liberaban a éste de la obligación de pagar intereses a los depositantes.

23. Junto con Roberto Murray, Borgo es uno de los más fuerres hombres de negocios de Centroamérica. Sus inversiones incluyen TACA, la más grande empresa aérea de Centroamérica y una de las ocho mayores de Anérica latina. A fines de 1994 Borgo se alejó de la presidencia por razones de salud, siendo designado en su reemplazo Alberto Hintz,

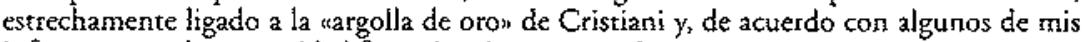
informantes, a la comunidad financiera internacional.

24. Roberso D'Abuisson, un extremista del anticomunismo vinculado desde los años serenta a los servicios de inteligencia de Escados Unidos, fue uno de los fundadores de los escuadrones de la muerte que actuaron desde esos años, y zambién fundador del partido ARENA. El informe de la Comisión de la Verdad lo responsabiliza del asesinato del arzobispo de San Salvador, Monseñor Oscar Arnulfo Romero, mientras éste celebraba misa una mañana de marzo de 1980, además de otras violaciones masivas a los derechos humanos. 
fue encabezada por Hugo Barrera, candidato a vicepresidente de ARENA y compadre de Armando Calderón Sol. Con él se fueron Guillermo Sol Bang (pariente de Calderón; otro de los fundadores de ARENA y miembros de su consejo directivo nacional); Alberto Mejía Alférez (ligado a Calderón por intereses empresariales y persona de su gran confranza), y otros. Muchos fueron los que pensaron que también Calderón Sol seguiría ese camino, pero éste prefirió permanecer dentro de ARENA acatando los dictados de D'Abuisson -quien, sin embargo, no escatimaba públicas preferencias por Alfredo Cristiani. Cuando asumió la alcaldía de San Salvador durante la presidencia de Cristiani, Calderón se dedicó a reagrupar a los elementos que habían salido del partido; Mejía Alférez se convirtió en su brazo derecho en la alcaldía. Este trabajo de reunificación sigue desde la presidencia. Hugo Barrera es actualmente viceministro de Seguridad Pública y otros amigos ocupan posiciones importantes: Mejía Alférez fue nombrado ministro de agricultura y Primer Designado a la Presidencia; Sol Bang preside la Comisión de Electricidad del Río Lempa; Juan José Domenech recibió la presidencia de ANTEL (la empresa estatal de telecomunicaciones que próximamente será privatizada). Posteriormente, al renunciar Calderón a la presidencia de ARENA, Domenech asumió ese cargo.

Los grupos empresariales y militares marginados por estos movimientos, vinculados a los servicios de seguridad, expresaron su frustración publicando casos de corrupción que abarcan al ex presidente Cristiani y a funcionarios proximos a Calderón. La voz cantante en esta reacción estuvo a cargo del coronel Sigfrido Ochoa y del político Kirio Waldo Salgado, dirigente de ARENA desde su fundación, ambos denuncian a Cristiani y a Calderón por traición a los ideales de D'Abuisson: una manera indirecta de proclamar su frustración por haber quedado fuera del juego. La renuncia de Calderón de la presidencia de ARENA puede interpretarse como un intento de aplacar los ánimos, pero, de todos modos, Salgado y un pequeño grupo salió de ARENA para formar un nuevo partido, el Partido Liberal Democrático, desde donde continúan denunciando casos de corrupción gubernamental ${ }^{25}$. Es de prever que las próximas privatizaciones ahondarán la competencia entre grupos empresariales, la misma que se reflejará en las filas de ARENA. El resentimiento abarca también a sectores de la FAES, que al ser desplazados de cargos de dirección de empresas estatales, pierden tradicionales vías de enriquecimiento.

La actitud de los conflictos dentro de ARENA y de la elite del poder en torno a cuestiones que no implican proyectos políticos en conflicto es ante todo una competencia por el acceso a recursos, cargos y recompensas, que puede ser interpretada como una ilustración patética de una clase dominante que se considera vencedora en el conflicto reciente y que puede darse el lujo de enfrascarse en estas pugnas internas sin riesgo de perder el poder.

25. En octubre de 1994 Mejia Alfétez debió renunciar a sus cargos debido a denuncias de corrupción de las que fue absuelto en marzo de 1995. Sin embargo, su salida del gabinete privó a Całderón de uno de sus más estrechos aliados. 
La crisis en los partidos políticos se suma al desmantelamiento del movimiento sindical, severamente golpeado por la contrainsurgencia, la guerra y la situación económica. Solamente el $11 \%$ de la fuerza de trabajo se encuentra sindicalizada, pero en el sector manufacturero la tasa es de apenas el $6 \%$, y en el sector privado público se encuentra mucho más desarroliado que en el sector privado. El nuevo escenario institucional ha favorecido, sin embargo, una cierta reactivación de las protestas y las movilizaciones de trabajadores, sobre todo en el sector de la maquila, con un importante involucramiento de mujeres.

\section{Mirando hacia adelante}

"La guerra no tuvo vencedores, pero la derecha ganó la paz". La afirmación pertenece a uno de los más lúcidos salvadoreńos y expresa con crudeza el estado de ánimo de buena parte de los actores y observadores del proceso de paz. Las divisiones y rupturas dentro del FMLN, las dificultades de su transformación en partido político, la lentitud de la reconversión de los ex guerrilleros en parlamentarios y administradores, abonaron el terreno para el fortalecimiento político de las elites en el nuevo escenario institucional. El avance desigual de la ejecución de los acuerdos, el menor énfasis asignado en ellos a las dimensiones socioeconómicas de la paz, y las rigideces de política definidas por la ejecución desde 1990 de un diseño macroeconómico monetarista comprometido con las agencias financieras multilaterales, ahondaron el desfase entre el proceso de democratización política institucional, y la reproducción de la dominación de clase de las fracciones modernizantes de la oligarquía salvadoreña.

En el pasado, la conjugación de autoritarismo político (incluyendo fraude electoral, violencia física, violación de derechos humanos, etc.) y deterioro social creb las condiciones para la insurgencia popular y la guerra que le sucedió. La democratización institucional elimina uno de aquellos factores; queda por ver qué gravitación habrá de ejercer en el nuevo contexto el mantenimiento del deterioro social. Vale decir en qué medida un proceso no revertido de empobrecimiento y exclusión social puede llegar a erosionar la legirimidad del nuevo orden institucional. Naturalmente, esta interrogante plantea como hipótesis implícita que el diseño actual de políticas económicas y sociales no será eficaz para neutralizar sus tendencias inmanentes a la exclusión social -es decir una ineficacia similar a la ya registrada en la mayoría de los países que han adoprado diseños similares-, si no se acepta la hipóresis de las tendencias inmanentes a la exclusión.

Hay que destacar, en primer lugar, la amplia desmovilización de las clases populares, resultado de dos décadas de insurgencia, guerra, contrainsurgencia, terrorismo de estado, desplazamientos forzados. La gente se siente harta de violencia, demanda estabilidad, y en este escenario el discurso del orden y la disciplina propalado por las agencias gubernamentales, por ARENA y en general por la derecha cala hondo en segmentos amplios de las clases subalternas. Hay en esto un factor subjetivo que se ha registrado asimismo en procesos simila- 
res: los grupos de población más golpeados por el conflicto quieren creer y necesitan creer que el conflicto terminó y que ya no hay razón para el enfrentamiento. Se explica asi que los candidatos de ARENA hayan triunfado incluso en las áreas que durante el conflicto se encontraron bajo control del FMLN y donde el FMLN reclutaba buena parte de su apoyo más militante (Chalatenango, Morazán, San Miguel, Usulután, Cabañas, etc.). ARENA es claramente el partido del orden: una percepción que también parece haber hecho suya la fracción escindida del FMLN (Partido Demócrata) aliado a ARENA en el pacto de San Andrés.

Las migraciones hacia Estados Unidos desempeñan un papel importante en la desmovilización al ofrecer una solución individual - al menos una solución teórica - a la falta de horizonte laboral o económico en el escenario de paz. Por su lado, el espectáculo de los conflictos internos en el FMLN y las rupturas, actúan para diluir la creencia en una alternativa al actual estado de cosas. Aunque la alternativa existiera, no está claro quién podría impulsaria institucionalmente. Uno de los aspectos más llamativos del actual panorama institucional de EI Salvador es, en efecto, que después de dos décadas de guerra insurgente, cuando finalmente es posible plantear iniciativas de progreso social sin arriesgarse a perder la vida, esas iniciativas no son hasta ahora planteadas. Una parte de la antigua insurgencia decidió sumarse a las iniciativas de la derecha, mientras la otra no puede avanzar más allá de los alcances originales de los acuerdos de paz.

En este sentido, El Salvador ilustra bien el panorama que se está configurando en varios páses de América latina, de disyunción creciente entre protesta social y comportamientos políticos. El deterioro de las condiciones de vida de sectores amplios de la población no se traduce en un alineamiento político de confrontación; la protesta se agota en el terreno social (huelgas, manifestaciones callejeras, revueltas locales, etc.), sin que el malestar y sus expresiones colectivas se traduzcan proporcionalmente en voto opositor. Fs difícil negar que muchos de los salvadoreños que en los años setenta y ochenta colaboraron con la insurgencia, votaron en 1994 por los candidatos de la derecha.

Sin esas dos décadas de guerra insurgente es difícil pensar que la democratización hubiera avanzado todo lo que avanzó en los últimos años, ni la "comunidad internacional" habría llegado a preocuparse como lo hizo por el autoritarismo y las atrocidades de las elites. Este es un mérito que nadie podrá disputar a los insurgentes. En lo inmediato sin embargo, esas mismas elites demuestran ser más capaces que los actores de vocación popular para sacar provecho del nuevo escenario. Esto no significa mayor vocación democrática de la oligarquía, sino mayor experiencia en el ejercicio del poder. 